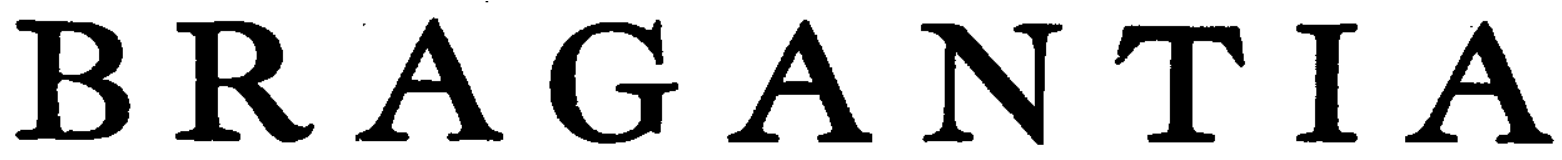

Boletim T'écnico da Divisão de Experimentação e Pesquisas IN STITUTO AGRONÔMICO

\begin{tabular}{lll}
\hline \hline Vol. 13 & Campinas, março de 1954 & N.० 2 \\
\hline \hline
\end{tabular}

\title{
UMA NOVA VARIEDADE DE STIFFTIA CHRYSANTHA MIKAN $\left(^{*}\right)$
}

D. M. DEDECCA,

Engenheiro agrônomo, Seç̧ão de Botânica, Instituto Agronômico de Campinas

\section{RESUMO}

Uma forma de Sifftia chrysantha Mikan, vulgarmente conhecida como jambeiro do. mato, rabo de cotia, etc., caracterizada pela coloração alaranjada dos seus capítulos, foi considerada pelo saudoso botânico patrício Joaquim Franco de Toledo como uma variedade, já que a espécie típica é citada na literatura especializada como possuidora de caṕtulos. vermelho-rubros. Toledo propôs o nome Stifftia chrysantha Mikan var. flavicans à nova. variedade, porém a sua morte inesperada impediu fósse publicada a descrição da nova. planta, o que é agora feito como homenagem à sua memória.

\section{1 - INTRODUÇÃO}

A planta que constitui o objeto do presente trabalho foi designada como nova variedade da espécie Stifftia chrysantha Mikan pelo eminente botânico Joaquim Franco de Toledo, tão lamentável e prematuramente roubado ao convívio dos seus amigos e discípulos. Infelizmente, em parte devido aos seus múltiplos afazeres e, por outro lado, dada a maneira rápida e sorrateira pela qual a morte o surpreendeu, Toledo, entre muitas contribuições valiosas inacabadas, deixou essa variedade para ser descrita. Por solicitação de alguns colegas do Instituto de Botânica de S. Paulo, de cuja Secção de Fitoteca Toledo foi chefe e responsável, e também como testemunho de gratidão pela amizade que o saudoso amigo bondosamente nos dispensava, é que nos decidimos a trazer à luz essa contribuição, a qual sem dúvida alguma teria. recebido uma forma melhor nas mãos hábeis de Joaquim Franco de Toledo.

\section{2 - DISCUSSÃO}

O gênero Stifftia, pertencente à tribo Muliseæ da família Compositæ, de acôrdo com Mikan (4), que foi o autor do gênero, e Baker (1), que monografou as compostas na Flora Brasiliensis, é representado, no Brasil, por cinco espécies. Essas espécies se distinguem entre si principalmente pelo tipo dos capítulos, se solitários nos ramos, tal como em S. chrysantha e $S$. condensata, se grandes e dispostos em corimbos bem abertos, como $S$. martiana e S. benthamiana, e, finalmente, se pequenos e dispostos em rácimos.

(*) Recebido para publicastio em 26 de outubro de 1953. 
pedunculados, como é o caso de $S$. parviflora. No grupo de espécies que apresentam capítulos solitários, $S$. chrysantha é caracterizada por ter o invólucro tìpicamente campanulado, e os capítulos constituidos de 30 a 40 flores, ao passo que $S$. condensata apresenta invólucro oblongo e o número de flores por capítulo não vai além de 10 ou 12.

Stifftia chrysantha Mikan é um bonito arbusto de até $2,5 \mathrm{~m}$ de altura, muito ramificado e densamente coberto por fôlhas de um verde escuro, no meio das quais se destacam os seus capítulos grandes e numerosos de côr vermelho-rubra, que é a côr do pappus das flores individuais. Na. descrição original da espécie, Mikan refere-se a êsse pappus nos seguintes termos: "pappus splendide rubello", significando com isto que a espécie, tal como êle a descreveu, é caracterizada por aquela coloração vermelho-rubra dos capítulos. Contudo, existe uma outra forma da mesma espécie cujas flores individuais do capítulo exibem um pappus amarelo-alaranjado ou côr de açafrão e que, igualmente, oferece um bonito efeito ornamental juntamente com as corolas de côr vermelho-alaranjada. De acôrdo com os seus característicos, essa forma sòmente pode ser incluida na espécie Stifftia chrysantha Mikan, porque ela apresenta capítulos solitários, invólucro campanulado e um número de flores variável de 30-40 em cada capítulo. $\mathrm{Na}$ verdade, De Candolle (3) a descreve como sendo realmente Stifftia chrysantha e Ihe atribui "pappus croceus", o mesmo acontecendo com Bentham e Hooker (2), que assim a descreveram: "pappo longo, croceo-nitente speciosissima".

Toledo, estudando um material semelhante ao investigado pelos autores acima referidos, isto é, caracterizado por apresentar o pappus de côr acentuadamente amarelo-alaranjada, e prendendo-se estreitamente à descrição original de Stifftia chrysantha tal como. Mikan a elaborou, concluiu por julgar serem as plantas de capítulo alaranjado uma variedade da espécie típica Stifftia chrysantha Mikan, e propôs o estabelecimento dessa variedade, assim se expressando :-

"A specie typica recedit, pappis coloratione splendide flavicanti".

$$
3 \text { - DEESCRIÇÃO BOTẦNICA }
$$

Stifftia chrysantha Mikan var. flavicans Toledo, nov. var. (Estampa 1).

Frutex ramosissimus, erectus, glaber circa $2,5 \mathrm{~m}$ altus ; folia opposita breviter petiolata, oblongo-lanceolata acuta vel breviter acuminata, rigidula, utrinque viridia, glabra, 7-15 $\mathrm{cm}$ longa 3-6 $\mathrm{cm}$ lata. Capitula magna solitaria breviter pedunculata 30-40-floris. Involucrum late campanulatum, multiseriatum, bracteis viridis rijidis adpressis glabris intimis lineari-oblongis 20-23 mm longis 5-7 $\mathrm{mm}$ latis, centralibus oblongis $14-17 \mathrm{~mm}$ longis'6-7 $\mathrm{mm}$ latis, exterioribus ovatis brevioribus angustioribusque. Receptaculum nudum, arcuatum, foveolatum. ' Corolla tubulosa, tubo cylindrico ima basi aurantiaca superne aurantiaco-rub̈ella segmentis linearibus revolutis, 40-46 cm longa. Antheræ pallide flave basi sagittatæ, auriculis longe caudata, 14-20 mm longæ. Styli rami subcomplanati lineares. Pappus multiserialis splendide flavicantis setis 30-40 min longis permultis flexuosisque. Achonia cylindrica angulata glabra 10-costata 14-20 $\mathrm{mm}$ longa. 
A specie typica imprimis pappis coloratione splendide flavicanti differt.

Tipo - Herbário do Instituto de Botânica, São Paulo (SP), sob n. ${ }^{\circ}$ 51749.

(vide infra).

Malerial examinado - A. S. Lima ex Herb. Instituto Agronômico do Estado São Paulo, n. ${ }^{\circ} 7306$ (SP 51749 TYPUS) - Estado de São Paulo: Campinas, cultivado no parque do Instituto Agronômico, fl. 24-2-1944 ; B. Pickel n. ${ }^{\circ} 3487$, São Paulo, cultivado no Horto Florestal de Tremembé, fl. 15-7-1949.

Arbusto muito ramificado, erecto, atingindo até $2,5 \mathrm{~m}$ de altura, lembrando no seu conjunto um jambeiro, de onde lhe veio provàvelmente a denominação vulgar de jambeiro do mato. Fôlhas opostas, curto-pecíoladas, glabras, oblongo-lanceoladas, ápice agudo ou curto-acuminado, textura rija, verde intensas em ambas as faces, peninervadas, bordos inteiros, $7-15 \mathrm{~cm}$ longas e 3-6 $\mathrm{cm}$ largas. Capítulos grandes, solitários, curto-pedunculados, constituídos de 30-40 flores. Invólucro largo-campanulado, multiseriado, verde-amarelado, as brácteas internas oblongo-lineares, $20-23 \mathrm{~mm}$ longas e 5-7 mm largas, as medianas, oblongas, $14-17 \mathrm{~mm}$ longas e 6-7 mm largas, e as mais externas, ovais, $6-8 \mathrm{~mm}$ longas e $5-6 \mathrm{~mm}$ largas. Receptáculo nu, arredondado, alveolado. Corolas tubulosas, apresentando um limbo curto formado de 5 segmentos lineares e revolutos, amarclo-alaranjadas na base e vermelho-alaranjadas e dilatadas na metade superior, glabras, 40-46 mm longas. Anteras de base sagitada e aurículas longo-caudadas, amareladas, eêrca de $25 \mathrm{~mm}$ longas. Fstilos de ramos lineares, longamente exsertos, juntamente com as anteras. Aquênios glabros, cilíndricos e angulosos, 10-nervados, 14-20 mm longos. Pappus multiseriado, cerdas numerosas, flexuosas, amarelo-alaranjadas, $3 \tilde{0}-40 \mathrm{~mm}$ longas.

Floresce pràticamente durante o ano todo, constituindo uma excelente planta para a ornamentação de jardins. Apresenta, contudo, o inconveniente de produzir poucas sementes ; no máximo 3-5 frutos férteis têm sido encontrados por capítulo, e, ainda assim, a obtenção de novas plantas por meio das sementes é muito demorada. Provàvelmente a sua propagação por estacas deverá dar melhores resultados. Para a coleta de sementes deverão ser escolhidos os capítulos sêcos, dos quais as corolas já se desprenderam e colhidos os aquênios que se apresentam verdes e túrgidos ou volumosos, fàcilmente distinguidos dos frutos estéreis que se mantêm cilíndricos e delgados (Estampa 1, figs. $a$ e $b$ ).

Nomes vulgares - Jambeiro do mato, rabo de cotia, diadema, esponjeira.

\section{A NEW VARIETY OF STIFFTIA CHRYSANTHA MIKAN}

\section{SUMMARY}

Stiffia chrysantha Mikan, a shrub about $2.5 \mathrm{~m}$ tall, is characterized by presenting large, solitary, 30-40-flowered heads, bell-shaped involucre, and individual flowers surrounded by a dark red pappus. The heads contrast in color with the green foliage, rendering the plant very useful for ornamental purposes.

A plant was found which presented all the characteristics of Stifftia chrysantha except for the pappus which was of a bright orange-yellowish color. The late botanist J. F. Toledo 
considered this plant as a new variety and proposed the name Stifftia chrysantha Mikan var. flavicans, stating :

"A specie typica recedit, pappis coloratione splendide flavicanti". His unexpected death prevented him from publishing a complete description of the new variety. This is now being done as a posthumous tribute to him.

\section{IITERATLRA CITADA}

1. BAKER, J. G. In Von Martius, C.F.P. Flora brasiliensis:VI(3). Compositae. Leipzig, 1884. p. 350-352.

2. BENTHAM, G. \& HOOKER, J. D. Genera Plantarum:II. Londres, 1873-1876. p. 491 .

3. DE CANDOLle, A. P. Prodromus :VII. Paris, 1838 p. 26.

4. MIKAN, J. C. Delectus florae et faunae brasiliensis :I. Viena, $1820 . \quad$ p. 113. 


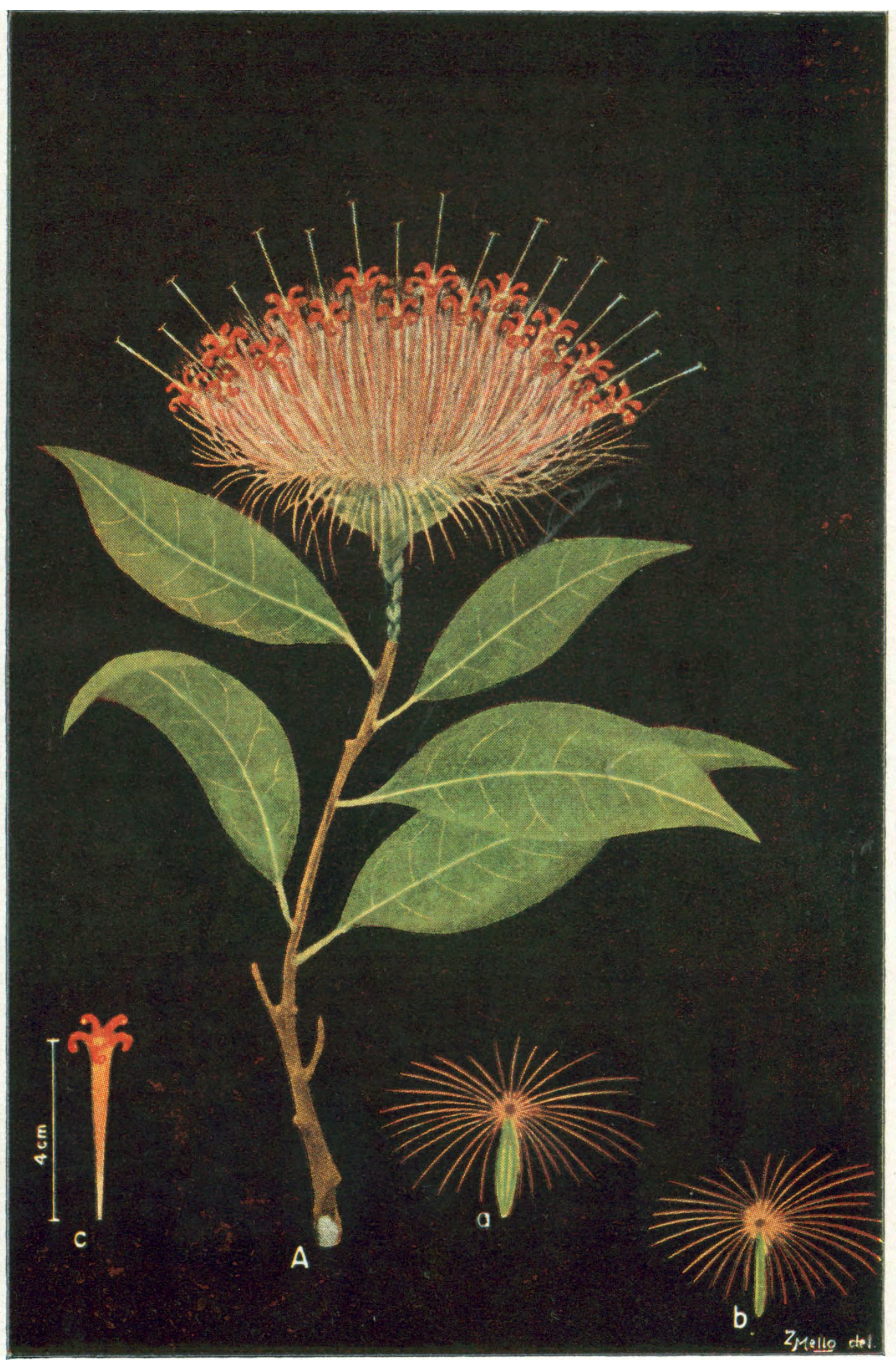

A - Ramo florífero; $a$ - aquênio fertil; $b$ - aquênio estéril; $c$ corola isolada. 